\title{
Correction to: The Accuracy of SPECT/CT for Diagnosing Lumbar Zygapophyseal Joint Pain: a Systematic Review
}

\author{
Aaron Conger ${ }^{1} \cdot$ Taylor Burnham $^{1} \cdot$ Rebecca A. Speckman $^{1,2} \cdot$ Dustin Randall $^{3} \cdot$ Raquel Reisinger $^{1} \cdot$ Quinn Tate $^{1}$. \\ Ryan Spiker ${ }^{4}$ Byron Schneider ${ }^{5} \cdot$ Daniel M. Cushman ${ }^{1} \cdot$ Zachary L. McCormick $^{1}$
}

Published online: 23 December 2019

(C) Springer Science+Business Media, LLC, part of Springer Nature 2019

\section{Correction to: Curr Phys Med Rehabil Rep. https://doi.org/10.1007/s40141-019-00237-4}

The original version of this article unfortunately contained a mistake in the authorgroup section. Author Byron Schneider's family name was incorrectly presented as "Schnieder".

The original article has been corrected.

Publisher's Note Springer Nature remains neutral with regard to jurisdictional claims in published maps and institutional affiliations.

The online version of the original article can be found at https://doi.org/ $10.1007 / \mathrm{s} 40141-019-00237-4$

\footnotetext{
Aaron Conger

aaron.conger@hsc.utah.edu

1 Division of Physical Medicine and Rehabilitation, University of Utah, 590 Wakara Way, Salt Lake City, UT 84108, USA

2 Department of Veterans Affairs Salt Lake City Health Care System, Salt Lake City, UT, USA

3 Oakland University William Beaumont School of Medicine, Rochester, MI 48309, USA

4 Department of Orthopaedics, University of Utah, Salt Lake City, UT, USA

5 Department of Physical Medicine and Rehabilitation, Vanderbilt University, Nashville, TN, USA
} 